\title{
Problematic practice in integrated impact assessment: the role of consultants and predictive computer models in burying uncertainty
}

\author{
Ronlyn Duncan
}

\begin{abstract}
It is well known in impact assessment that predictive model outputs will be as credible as their inputs and that model assumptions will drive outputs. What is less well known is how the practice of integrated impact assessment with its pervasive use of predictive computer models and multiple teams of consultants can influence evidence relied upon in deliberations over the impacts and benefits of major projects. This paper draws on an integrated impact assessment of a major energy infrastructure project in Australia known as Basslink to examine the epistemic implications of current practice. It will be argued that what has become standard procedure can serve to diminish the disclosure of prediction uncertainty.
\end{abstract}

Keywords: Australia, Basslink, predictive computer models, certainty trough, integrated impact assessment, prediction, uncertainty, simulations.

$\mathrm{P}$ ROJECT-BASED INTEGRATED impact assessment requires proponents to document existing social, economic and environmental conditions and present predictions about expected post-development changes together with possible outcomes of mitigation (Glasson et al, 2005; Thomas, 1998). To this end, it has become standard practice for proponents to engage multiple teams of consultants and scientists across a range of specialised fields to develop what eventually becomes a unified impact assessment statement.

It has also become standard practice for these actors to use often complex computer models to derive the requisite quantified predictions about future conditions (Wachs, 1990: 148; Glasson et al, 2005: 130). For instance, a raft of computerised predictive

Ronlyn Duncan is a lecturer in the School of Geography and Environmental Studies, University of Tasmania, Private Bag 78, Hobart, Tasmania 7001, Australia; Email: Ronlyn.Duncan@ utas.edu.au; Tel: +613 6226 2054; Fax: +613 62262989. economic and environmental models were used in the assessment of Basslink, an undersea electricity cable that now links the island state of Tasmania to the Australian mainland.

The Basslink draft Integrated Impact Assessment Statement (IIAS), over 6,000 pages in length, involved no less than 30 consultant firms (NSR Environmental Consultants Pty Ltd, 2001: 1.12-1.14, 2.6-2.7). Notably, predictions about future environmental impacts and scenarios for mitigation were derived from the modelling of the economic aspects of the project. This approach, which directly linked predicted environmental conclusions to the project's economic forecasts, appeared to give the proponent's case for Basslink considerable coherence (see JAP, 2002a; 2002b). It has also meant that the scrutinised environmental conclusions were anchored to an economic future that, as yet, has not eventuated.

Hence, the Basslink case study highlights the challenge of integrating not only the assessment of the social, economic and environmental aspects of a major project (Duncan and Hay, 2007), but also the 
evidence on which decisions are based. The analysis presented in this paper seeks to answer the question: what are the implications of what has become standard impact assessment practice for process transparency and proponent accountability?

\section{Predictive computer models}

Before moving on, I would like to clarify what is meant by 'predictive computer modelling'. A model is defined by Hartmann (1996: 4 citing Guetzkow et al, 1972) as "a set of assumptions about some system". The assumptions can be derived from 'general theory' or they can be 'idealized' representations (Hartmann, 1996: 4). Models can depict a system at rest (static) or changing over time (dynamic).

Once a system has been defined, its dynamics are described by simulations. Hartmann (1996: 5) explains that a "simulation results when the equations of the underlying dynamic model are solved". According to Hartmann (1996 citing Niehans, 1990), models have their origin in the late nineteenth century when theoretical physicists used mathematics to build models to describe and understand nature. These models helped scientists investigate natural phenomena and derive what are now well-known mathematical relationships.

The 'model-method' was extended to economics in the decades that followed (Hartmann, 1996: 3). Statistical and repetitive simulations using random numbers to approximate a real system were carried out from the late 1940s and applied to atoms, warfare and industrial productivity (Smith, 1999). These days, models and simulations are "used in nearly every engineering, scientific and technological discipline" (Smith, 1999: 4), and for a good reason they allow a system to be constructed, investigated, reconfigured and tested with relative ease.

Smith (1999: 3) notes that system models have "proved to be more cost effective, less dangerous, faster, or otherwise more practical than experimenting with the real system". Simulations allow an analyst to experiment with a model to test a system's behaviour under varying conditions and with alternative interventions. It is these attributes that make models and simulations so compelling in integrated impact assessment, for both proponents and decision-makers.

Notwithstanding their considerable utility, it is important to acknowledge the limitations of predictive models and simulations, as these are particularly relevant in the context of impact assessment where the stakes are high and there is usually no turning back after a decision has been made. For instance, despite constantly increasing computing power, we remain unable to accurately represent in a model the complexity of real economic and environmental systems and, in particular, their interactions (Smith, 1999).

In addition, values permeate models and simulations, as decisions always have to be made about what to put in, what to simplify and what to leave out. Furthermore, data inputs are often limited, unavailable, difficult and expensive to obtain or in need of recalibration (Smith, 1999; see also Irwin and Wynne, 1996).

In this paper I use the term 'predictive computer modelling' with the intention of encapsulating the act of both building a system model and conducting simulations with it. I do so also to emphasise the fact that models used in impact assessment are usually computer-based and the contingent nature of their predictive outputs.

\section{The pitfalls of practice}

In integrated impact assessment, although predictive computer modelling allows proponents to present with considerable clarity environmental impact and mitigation scenarios as well as the economic and social aspects of major projects (De Jongh, 1988; Glasson et al, 2005; Thomas, 1998), their use poses a number of challenges. For instance, in addition to the issues discussed above, our habitual misinterpretation and misuse of numbers impedes transparency and accountability (Thomas, 1998: 154-160).

Porter (1995) maintains that numbers are commonly thought to derive from the application of impersonal mathematical rules and thereby eliminate the exercise of judgement. Porter (1992a: 640) describes quantification as a "technology of distance", as it has served to encourage confidence when one cannot be present to check all the details or be sure how answers have been arrived at. As such, quantification provides a means for (often misplaced) trust to be extended over long distances (Porter, 1995; 1992b).

In the politically charged arena of integrated impact assessment, our use (and misuse) of numbers becomes crucial. Indeed, a number of authors reporting on environmental impact assessment and the integrated assessment of major projects have found that prediction claims often appear much more robust than is warranted (e.g. Beder, 1993; De Jongh, 1988; Glasson et al, 2005: 135; Spry, 1976; Thomas, 1998: 26).

Moreover, Flyvbjerg et al (2002; 2003) and Wachs (1990) argue that in the assessment of infrastructure projects numbers are readily manipulated and misrepresented by proponents, consultants and governments to present projects in a favourable light or simply to get projects over the approval line from where there is no turning back.

Tennøy et al (2006: 52) provide a useful review of the dimensions of prediction uncertainty in environmental impact assessment and demonstrate quantitatively that the disclosure of uncertainty diminishes as knowledge claims move through the impact assessment process. Specifically, in respect of major infrastructure projects in Norway, Tennøy et al (2006: 50) investigated (a) the disclosure of uncertainty, and (b) the extent to which assumptions and data limitations were divulged in assessment documents. 
In the politically charged arena of integrated impact assessment, our use (and misuse) of numbers becomes crucial. Prediction claims often appear much more robust than is warranted

In terms of (a) they identified four levels of the expression of uncertainty in three categories of process documents, and calculated that although uncertainty was acknowledged in most initial prediction documents (i.e. technical reports), such was not the case in around two-thirds of the impact assessment statements and final determinations.

In terms of (b), assumptions and data limitations were discussed in more than two-thirds of the prediction documents, but in only a quarter of the impact statements and even less in the final determinations. Tennøy et al (2006: 52) conclude that "decision-makers are not made aware of the prediction uncertainty" and "EIA predictions thus appear more certain than they are".

A divergent inference to be drawn from the former conclusion of Tennøy et al (2006) is that proponents, proponents' consultants and decision-makers have a vested interest in making public documents and their decision commentary appear defensible and politically palatable. Consequently, these actors often endeavour to minimise the public disclosure of uncertainty; see, for example, Flyvbjerg et al (2002; 2003), Hilgartner (2000), Jasanoff (1987; 1990), Shackley and Wynne (1996), and Wachs (1990).

On this basis, while it would be the case that predictions appear more certain than is warranted as concluded by Tennøy et al (2006), the extent to which decision-makers are not made aware of uncertainty is a moot point which is explored in this paper.

\section{Research scope}

The work of Tennøy et al (2006) provides a departure point for this paper. Here, I focus on what has become standard integrated impact assessment practice - namely, the pervasive use of predictive models by multiple teams of consultants across a range of specialised fields. My analysis draws on ideas that probe the process of knowledge production. It seeks to contribute to explaining how the disclosure of uncertainty can diminish as the assessment process proceeds.

Furthermore, in accepting that actors' endeavours to minimise the public disclosure of uncertainty is an important part of the knowledge production story (see Jasanoff, 1987; 1990; Hilgartner, 2000; Shackley and Wynne, 1996), I examine how it would be the case that decision-makers are not made sufficiently aware of prediction uncertainty, as concluded by Tennøy et al (2006).

A second point of departure is the issue of proponent assumptions. Tennøy et al (2006) recommend that these assumptions should be better communicated and their specifics deliberated upon in a much more meaningful and accountable manner. The important point is made by Tennøy et al (2006: 52) that it is "difficult for others to realise that quite different results could have been reached if other input data and assumptions had been chosen”. In other words, from alternative starting points, a project could look vastly different.

Relatedly, De Jongh (1988: 66) distinguishes 'uncertainty of prediction' from 'uncertainty of values'. Whereas the former would be dealt with by empirical research, the latter would require a personal approach with "scoping, communication, participation, negotiation and mediation" (De Jongh, 1988: 80). De Jongh's recommendations point to the intangible and contingent nature of values issues and the need for their deliberation prior to empirical investigations.

The Basslink case study illustrates the defining role that a proponent's formative value frameworks can play in directing choices on which numbers to select and which numbers to ignore for input to and output from predictive models (Irwin and Wynne, 1996).

The significance of this paper is that it demonstrates the existence of knowledge production blindspots and examines their epistemic implications for the practice of integrated impact assessment. I argue that it is imperative for impact assessment practice to be centred on procedures that openly confront uncertainty and work with rather than against it (see Geneletti et al, 2003; Gibson et al, 2005; Glasson, 1994; Strand, 1999; Tennøy, 2008; Wynne, 1992a for more discussion on addressing uncertainty in general and in impact assessment specifically).

\section{Analytic framework}

My analysis uses as a case study the Basslink integrated impact assessment process conducted in the state of Tasmania during 2000 and 2002, and also events that have precipitated since the project's commissioning in 2006. It draws on my review, comparison and evaluation of documents tabled with Tasmania's Resource Planning and Development Commission (RPDC), an independent statutory body established to oversee the assessment of projects of state significance. The documents examined included:

- the Basslink draft IIAS (NSR Environmental Consultants Pty Ltd, 2001);

- the assessment panel's IIAS critique report (Brown and Root Services Asia Pacific Pty Ltd, 2001); 
- the proponent's economic reports (Connarty, 2001a; 2001b; HEC, 2001a; 2001b);

- initial and update environmental reports (Davidson and Gibbons, 2001a; 2001b; Davies, 2001; Davies and Cook, 2001; Koehnken et al, 2001; Koehnken, 2001; Howland, 2001; Kriwoken, 2001a; 2001b);

- the proponent's overview and summary reports (Locher, 2001a; 2001b);

- the joint proponent's consultant reports (IES, 2000a; 2000b; URS New Zealand Ltd, 2001; CREA, 2000);

- the assessment body's draft and final reports (JAP, 2002a; 2002b);

- the final IIAS (NSR Environmental Consultants Pty Ltd, 2002); and

- evidence tendered at the public hearings in October and November 2001, which I attended.

I was given permission by the RPDC to transcribe recorded evidence that was not publicly available. More recent events have been reported in the Tasmanian media and documented in the proponent's annual reports.

I draw theoretical insight from constructivist theories of knowledge in the field of Science and Technology Studies (STS). In general, constructivist-STS critically analyses the methods, claims and institutional contexts of science, as well as the modes and consequences of the translation and deployment of scientific knowledge claims within and beyond the domain of science (Irwin, 2001).

In particular, my analysis looks at the Basslink assessment process from an epistemological perspective. An epistemology describes a particular conception of how knowledge is produced and the factors which contribute to its extent and validation - in other words, how it is that we know (Gubrium and Holstein, 2000; Irwin, 2001).

Currently, western science tops the knowledge hierarchy of intellectual authority (Bohme, 1997). In terms of epistemology, this status rests on the premise that science can and does produce 'rational' and 'objective' knowledge (Irwin, 2001). In the arena of impact assessment these authoritative categories are used freely in defence of a proponent's conclusions.
As already alluded to, however, researchers in the fields of impact assessment and STS have shown that such claims are often difficult to defend when underlying assumptions are unearthed and challenged (for example, see Flyvbjerg 2002; 2003; Wachs, 1990 in impact assessment and Jasanoff, 1987; 1990; Hilgartner, 2000; Wynne, 1992b in STS).

The foundational theoretical premise for this analysis comes from Collins $(1987 ; 1988)$ who argues that the interpretation of science in public draws its credibility from the distance created between the performance of science and its audience. He makes the following observation (Collins, 1988: 726):

Close proximity to experimental work, particularly where there is an element of controversy, makes visible the skilful, inexplicable and therefore potentially fallible aspects of experimentation, it lends salience to the web of assumptions that underlie what counts as an experimental outcome ... Time spent on, or near, the seat of controversy leads to the conclusion that the only reason that certainty is ever attained in science is because this privileged viewpoint is the preserve of so few. Thus, that there is more certainty when distance from the cutting edge of science is maximized is not just initially surprising: it appears that distance from the cutting edge of science is the source of what certainty we have.

In essence, Collins argues that with greater distance from the location of knowledge production, the less uncertainty one will be exposed to and the less uncertainty one will see (or see the need to be concerned about).

Collins's insight is applied in the work of MacKenzie (1990: 419; see also Duncan, 2003; Latour and Woolgar, 1979; Latour, 1987) which investigates the sociological and institutional dimensions of technology, in particular the development of weapons guidance systems in the United States. MacKenzie (1990: 372) maintains that there is a variable relationship between actors' perceptions of uncertainty and their distance from the research front, forming what he has termed the 'certainty trough' (Figure 1). ${ }^{1}$

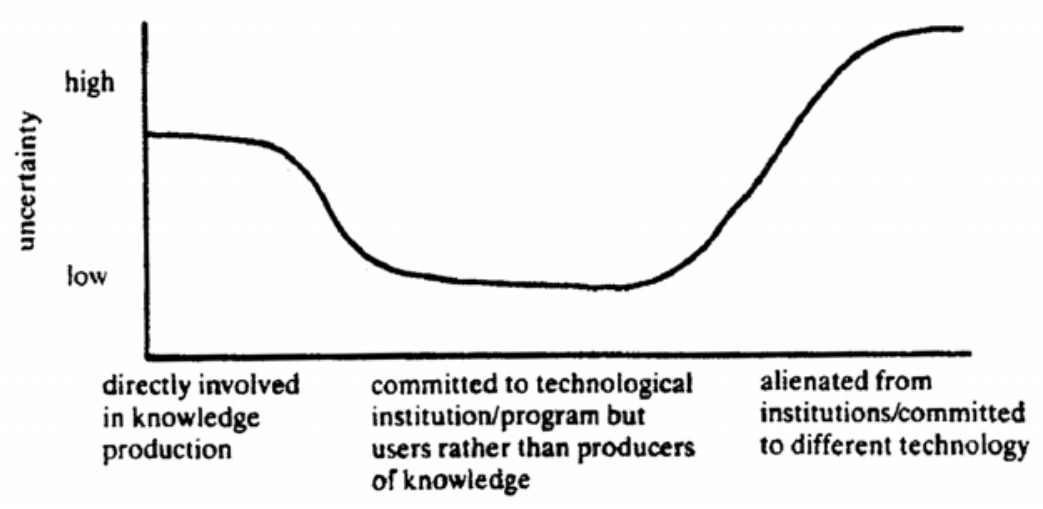

Figure 1: The certainty trough

Source: MacKenzie (1990: 372) @ MIT Press 
To provide an initial overview, Figure 1 depicts 'social distance' from where knowledge is produced from left (closest) to right (most distant) along the $x$-axis, and uncertainty from low to high along the $y$-axis (MacKenzie, 1990; 2007: 1). On the left, actors are closely involved in the production of knowledge - for example, developing and applying methodologies; designing, constructing and conducting experiments; or carrying out observation, data collection and statistical analyses. Uncertainty here is in the medium to high range.

On the right, at greatest distance from the knowledge production source, uncertainty is at a very high level. The middle section is conceived as the 'certainty trough': it is here that uncertainty is at its lowest and, correspondingly, certainty is at its highest (MacKenzie, 1990: 372). Notably, in this zone, uncertainty decreases with distance. MacKenzie (1990: 419) suggests that the certainty trough describes a 'distribution of certainty' on the basis that actors' proximity to the location of knowledge production will influence the attribution of the credibility of knowledge claims with which they are presented.

The relationship identified by MacKenzie (1990) indicates that those closest to where knowledge is constructed (i.e. those doing the experiments or working with the primary data) will attribute an unexpectedly high level of uncertainty to aspects of their work (MacKenzie, 2007). For instance, although not usually publicly expounded, scientists will be cognisant of the uncertainties in their experiments, data, methods and findings.

As MacKenzie (1990: 419) puts it, for these 'insiders' there is "doubt of a more private and more limited, but nevertheless real, kind" (MacKenzie, 1990: 371); importantly, these actors are conceived as knowledge 'producers' (MacKenzie, 1990: 372). He suggests that, in a controversy, the uncertainties held by these knowledge producers, if identified, can be used by those in opposition to undermine claims supporting a technological development.

On the right of Figure 1 are those at greatest distance from where knowledge is produced. These actors are not the focus of this paper but it is important to note that they will perceive the highest level of uncertainty. Committed to an alternative technology, strategy or project, these 'outsiders' will be alienated from the existing proposal and, in all likelihood, the institutions recommending it (MacKenzie, 1990; 2007: 1). In the context of impact assessment, interest groups opposed to a particular project or alternative proponents would be located here.

Taking a closer look at the certainty trough located between those closely involved in knowledge production and those 'alienated' from it, the actors here are constituted as 'program loyalists' as this inbetween group "believes what the brochures tell them" (MacKenzie, 1990: 371). In the context of impact assessment, they might be proponents that commissioned studies or governments in support of a project being assessed.

\section{Knowledge 'producers' would be aware of the contingencies in their predictions, whereas knowledge 'users' have to rely on others to sufficiently communicate the uncertainties to them}

They might also be decision-makers, members of the public or interest groups not necessarily opposed to the project. Such actors are knowledge 'users', not its producers nor its antagonists (MacKenzie, 1990: 372). Importantly, MacKenzie (1990: 419) argues that the durability of technical 'facts' is 'hardest' in the location of the certainty trough; without resources or reasons to unearth the contingencies, they are likely to fade from view.

To reiterate the distinction between knowledge 'users' and knowledge 'producers' (MacKenzie, 1990: 372), the former have to rely on others to sufficiently communicate the uncertainties to them, whereas the latter would be aware of the contingencies in their predictions and capable of reporting on them if called upon to do so.

What the 'certainty trough' shows us is that a disconnection occurs as knowledge claims move from the hands (or computers) of knowledge 'producers' to knowledge 'users' (MacKenzie, 1990: 372). In other words, by virtue of their distance from the location of knowledge production and the lack of an intimate connection with the experiments, testing or primary data, knowledge 'users' will attribute a relatively low level of uncertainty to the knowledge claims with which they are presented (MacKenzie, 1990: 372).

Shackley and Wynne (1995) found this to be the case in their study of the science/policy nexus in respect of climate change general circulation models. They conclude (Shackley and Wynne, 1995: 114, emphasis added):

The perceived certainty of knowledge claims of a research speciality is greatest some way from the actual site of knowledge production ... So, practitioners may attribute greater certainty to knowledge from another speciality than the practitioners in the first specialty would attribute to it themselves.

These insights are useful for examining the practice of integrated impact assessment where it is usual for an array of consultants and scientists from different fields to be pulled together by a proponent to produce, with the aid of a string of predictive computer models, an integrated impact statement. Such was 
the case with Basslink where predictive economic modelling outputs via several intervening iterations were translated into environmental model inputs and, subsequently, into predictions about environmental impacts on Tasmania's Gordon River, to which I will now turn.

\section{The Basslink project}

Basslink, Tasmania's 360-kilometre Bass Strait power cable, was approved by state and national governments in 2002 and commenced operation in May 2006. Basslink was built and is owned and operated by a private energy transmission company. Tasmania's hydro-generator, a corporatised government business enterprise (the proponent), pays the owner a facility fee to access the cable and has arrangements to settle arbitrage transactions across the link.

It was intended that the cable would allow the proponent to export its hydro-electricity for a premium price into Australia's National Electricity Market (NEM) at intervals of peak demand. By importing electricity into Tasmania from mainland sources at relatively low prices during intervals of low mainland demand, Tasmania could save its water resources to derive a premium price for its hydro-electricity when sold back into the NEM.
The assessment process that approved Basslink examined many issues. Among them, and the focus of this paper, was the extent to which Tasmania's participation in the NEM would change the operation of the Gordon Power Station, Tasmania's largest hydro-generation facility, which had been providing relatively stable base-load electricity for Tasmania.

It was expected that Basslink would change the power station's operations by the delivery of highly variable peak load into the NEM. These changes were expected to alter the volume and variability of water discharges from the Gordon Power Station down the Gordon River which runs through and forms part of the Tasmanian Wilderness World Heritage Area (TWWHA) (Connarty, 2001a; Locher, 2001a: 19). However, a lack of surplus water in Tasmania has meant that, so far, the cable has been used predominantly to import electricity from the mainland, rather than to export it (Locher, 2001a:25).

\section{Consultants, computer models and disaggregated data}

Figure 2 is an overview of evidence in support of the proponent's conclusions on environmental impacts for the Gordon River resulting from changes to electricity generation operations at the Gordon Power Station.

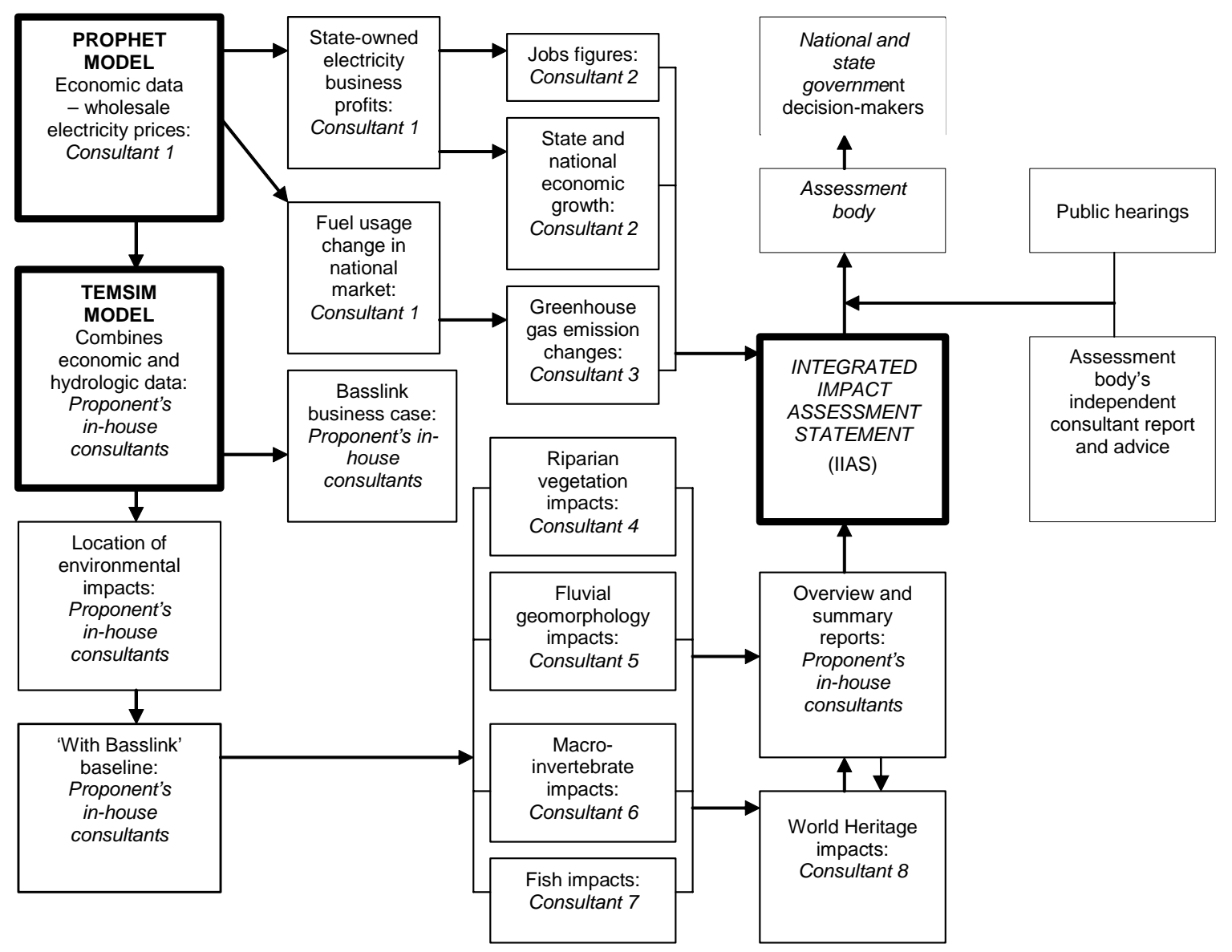

Figure 2. Overview of connections between predictive models, consultants' reports and process documentation in respect of conclusions on environmental impacts for Tasmania's Gordon River 
Notably, all of the Gordon River evidence was anchored to one predictive economic model known as PROPHET (Figure 2, top left), which was developed and used by Consultant 1 to study electricity markets. To provide further detail on the PROPHET model, the consultant required a number of data inputs to run its market simulations, such as load forecasts, network and regional loss factors, historical load traces, generator capacities, generator maintenance schedules, short-run marginal costs, demand management behaviour, generation forced outage rates and new generation plant assumptions (IES, 2000b: 10).

The model user can insert and alter these inputs (IES, 2002). Historical information was available for most of these aspects, although Consultant 1's 'estimates' were relied on for the last four in the list (IES, 2000b: 10; see also Duncan, 2004). The PROPHET model was marketed as (IES, 2002: 1):

The essential tool for Electricity Market participants. In a competitive market, it helps if you know the future. However, there will always be uncertainty in outcomes; who can predict the weather or plant breakdowns; but this does not mean you need to be totally unprepared. IES's PROPHET model enables you to heighten your awareness of possible developments.

It appears that although Consultant 1 did not envisage its model would eliminate uncertainty, it did advocate that it was possible and prudent to be wellinformed. To manage the uncertainty of weather, plant breakdowns and load variation, the model incorporates Monte-Carlo methods (IES, 2002: 1), which use random numbers and immense numbers of replications to derive statistical outputs from past experience of these events (see Smith, 1999; Hartmann, 1996).

Returning to Figure 2, PROPHET was used, inter alia, to predict changes in wholesale electricity prices (IES, 2000a; HEC, 2001b). Specifically, Basslink was expected to reduce such prices as it was injecting extra capacity into an undersupplied peak electricity market (Connarty, 2001a: 12; IES, 2000a). Using PROPHET, Consultant 1 calculated that the wholesale price of electricity would reduce in Tasmania by $6.7 \%$ by 2004 and $1.4 \%$ by 2010 (IES, 2000a: 1). It is important to note that these percentages represent changes from prices that were predicted to exist in the future without Basslink. For example, in 2004, without Basslink the wholesale energy price was forecasted to be $\$ 30$ per megawatt hour; with Basslink it was estimated to be $\$ 28$, and this difference represents a $6.7 \%$ reduction in the wholesale price (IES, 2000a: 8).

To calculate expected profit increases for Tasmania's state-owned electricity businesses with Basslink, Consultant 1 summed the reductions in wholesale electricity prices, its calculations of changes in retail margins and PROPHET's predictions of revenues arising from trading surplus energy across Basslink (IES, 2000a). The profit figures of \$15.2 million in 2004 and \$29.2 million in 2010 (IES, 2001a: 13) were then used by Consultant 2 as revenue inputs to its general equilibrium model to identify the number of jobs the project could be expected to deliver and the increase in economic growth at state and national levels (CREA, 2000).

PROPHET outputs were also used by Consultant 1 to derive 'functional relationships' about how the dispatch of different fuel types would change in the NEM with Basslink (IES, 2000b; URS New Zealand Ltd, 2001: 2-9). Such data were then passed to Consultant 3 to calculate overall market changes in greenhouse gas emissions that would be expected to arise from extra capacity in the NEM provided by access to Tasmania's non-carbon hydro-energy (URS New Zealand Ltd, 2001).

PROPHET's price projections were also passed to the proponent. Its in-house consultants incorporated the PROPHET outputs into its hydro-system optimisation model, which culminated in the Tasmanian Electricity Market Simulation Model (TEMSIM); see middle far left of Figure 2. TEMSIM modelled Tasmania's hydro-system and simulated how it could be expected to operate under Basslink conditions.

Coupled with water storage levels, the PROPHET price data was the driver of imports and exports in TEMSIM and, as such, triggered simulated discharges from the Gordon Power Station (Connarty, 2001a; Hydro Consulting, 2000: 25). The proponent's sensitivity analyses undertaken on Tasmanian load were controversial as the initial load variations chosen by the proponent were unrealistically low. These tests appeared to create more uncertainty than they resolved (HEC, 2001b: 2-6).

TEMSIM was utilised by the proponent for three tasks. First, it calculated revenues potentially attainable by the proponent from exports generated by the expected operation of Basslink in the NEM (HEC, 2001a: 4). Its outputs were then used to develop and continually update the proponent's business case for Basslink (House of Assembly, 2003).

Second, TEMSIM was used at the outset of the proponent's environmental investigations to identify areas of the hydro-system that could be most affected by the operation of Basslink, and which would require studies for the impact assessment process (Hydro Consulting, 2000). Third, TEMSIM was used to predict the magnitude of environmental impacts from changes in hydro-generation along the middle section of the Gordon River to which World Heritage Area protection legislation applied (Locher, 2001a; 2001b).

To estimate the environmental impacts, the PROPHET price data was transformed in TEMSIM by the proponent's in-house consultants into hydrologic data (Hydro Consulting, 2000: 25); this simulated the variability and magnitude of power 


\section{The proponent's business case and its assessments of economic and environmental impacts were all anchored solely to the findings of one predictive model. Each set of consultants was reliant upon the model outputs of another}

station discharges under Basslink conditions, and the information was translated into a 'with Basslink' baseline (Connarty, 2001a; Locher 2001a).

The baseline was then passed to environmental researchers engaged by the proponent (Consultants 4, 5, 6 and 7 in Figure 2) for use in their various environmental predictive models in the specialised fields of fluvial geomorphology, riparian vegetation, macro-invertebrates and fish (Clayton Utz, 2001). In these model iterations, the baseline data was transformed into yet another set of variables.

For instance, in the case of riparian vegetation, power station discharges were converted into hours of inundation to predict how long plants could survive waterlogging with the operation of Basslink (Davidson and Gibbons, 2001a). In terms of macroinvertebrates, power station discharges were used to calibrate risk bands for habitat change to gauge how Basslink could affect the river's macrofauna (Davies and Cook, 2001). Using their respective calculations, the environmental researchers also made recommendations on mitigation options (Davidson and Gibbons, 2001a; Davies and Cook, 2001; Koehnken et al, 2001; Howland, 2001).

In a final iteration, the environmental researchers' reports were integrated by the proponent's in-house consultants into a summary report (Locher, 2001a) and an overview report (Locher, 2001b). Duncan (2006) and Duncan and Hay (2007) argue that this process of integration served to contextualise the researchers' environmental conclusions with the proponent's operational, economic and political imperatives which, consequently, lessened the cogency of their findings.

Both sets of documents were reviewed by Consultant 8, the proponent's World Heritage Area (WHA) expert (Kriwoken, 2001a; 2001b). The critical issue for the proponent was whether the overall predicted Basslink impacts were likely to be determined by the assessment body to contravene WHA protection legislation (Duncan, 2006). Consultant 8 determined that Basslink would not compromise the TWWHA values (Kriwoken, 2001a; 2001b).

In summary, the proponent's business case for Basslink and its assessments of the location and magnitude of environmental impacts, state-owned electricity business profits, wholesale electricity price changes, state and national macro-economic projections for jobs and economic growth, changes in overall greenhouse gas emissions and WHA impacts were all anchored solely to the findings of one predictive economic model, PROPHET, which was described by the assessment panel's own consultants as "not detailed or explained" (Brown and Root Services Asia Pacific Pty Ltd, 2001: 9-40).

\section{Using the certainty trough to identify the knowledge disconnections}

To examine the implications for process transparency and proponent accountability of what has become standard integrated impact assessment practice, the 'certainty trough' proposed by MacKenzie (1990: 372) is a useful heuristic. I use it to trace the mobility of knowledge claims, their durability and their disconnection from their source of production in the context of impact assessment. I also use it to shed light on how assumptions, uncertainty and values (De Jongh, 1988) can become buried within what are proclaimed by proponents as 'scientific' and therefore 'independent' conclusions about the impacts and benefits of major projects.

Using the certainty trough, Figure 3 shows how the attribution of uncertainty varied between Consultant 1 as the knowledge producer of PROPHET's outputs (medium- to high-range uncertainty) and the subsequent users of its outputs (low-level uncertainty) (MacKenzie, 1990: 372).

Figure 3 also overlays multiple certainty troughs to depict the cascade of interconnections between the teams of consultants and subsequent actors set out in Figure 2. ${ }^{2}$ Here we can see how the various sets of consultants that were each required to undertake a particular piece of work and reliant upon the model outputs of another were constituted simultaneously as knowledge 'producers' and knowledge 'users' (MacKenzie, 1990: 372).

As a result, at each translation step the contingencies arising from the assumptions and values embedded in PROPHET and TEMSIM were progressively cordoned off from each subsequent team. In effect, the recipient of another team's model outputs was, willingly or not, constituted at increasing distance away from the location of knowledge production and, thereby, within the certainty trough (MacKenzie, 1990: 372).

In addition, Figure 3 combines the troughs to illustrate the compounding nature of the foundational reliance on the PROPHET outputs. When the troughs are combined and visualised as 'in phase', the implications are acute - both the peaks and troughs are amplified, as depicted (although somewhat exaggeratedly) by the dashed line in Figure $3 .^{3}$ In these circumstances, the certainty trough becomes a potentially irrevocable breach for actors constituted as knowledge users (MacKenzie, 1990: 372). 


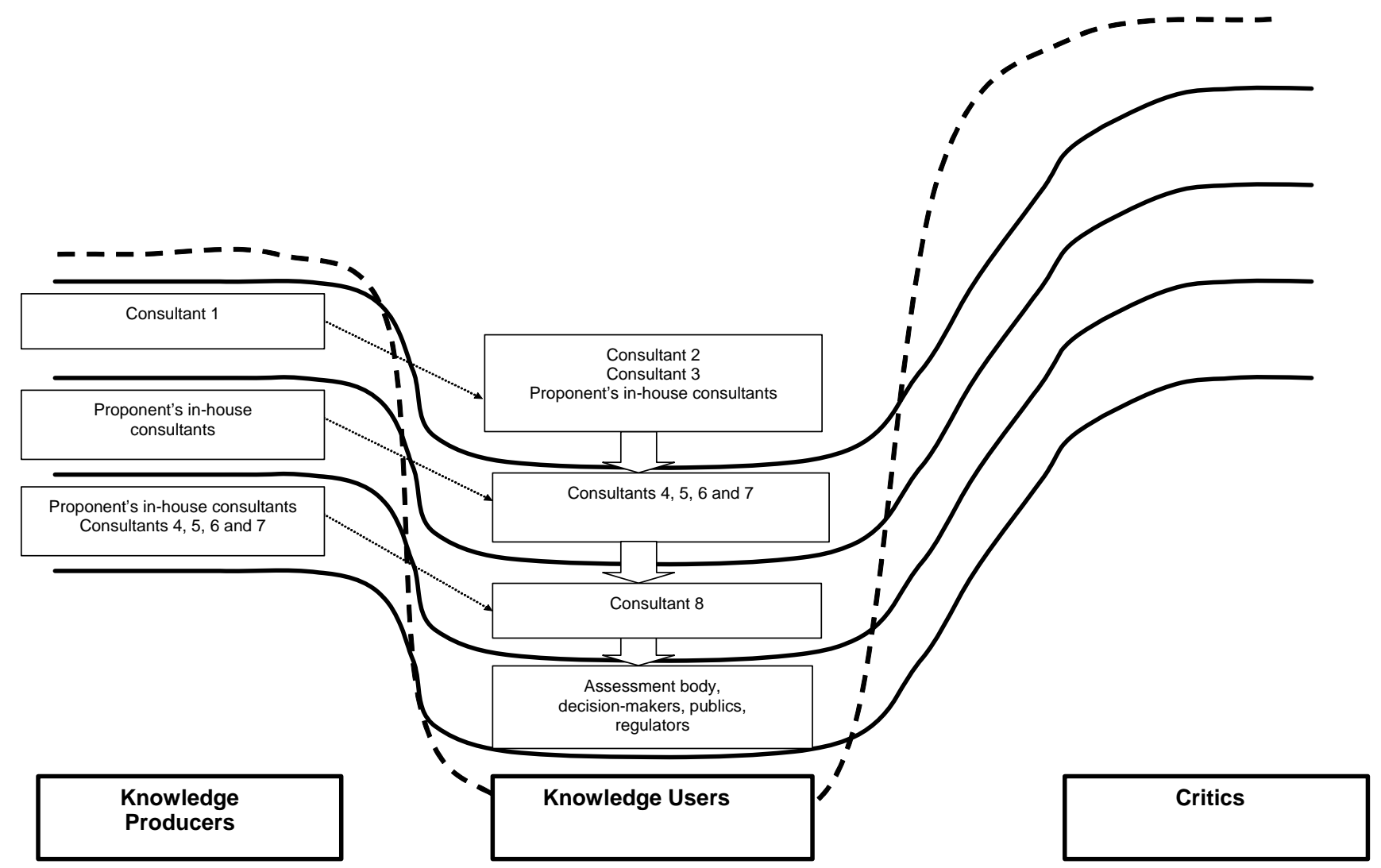

Figure 3: Overlaid certainty troughs (solid curves) and combined certainty troughs (dashed curve)

In the case of Basslink, all actors were knowledge users, with the exception of Consultant 1 upon whose model outputs all the others were contingent.

The following example from the Basslink process illustrates how distance from the location of knowledge production can serve to disconnect knowledge claims from their contingencies and, effectively, make them appear more reliable than is warranted. The consultants commissioned by the assessment body to critique the Basslink draft IIAS raised the crucial connection between TEMSIM (and by implication, PROPHET) and all of the Gordon River environmental studies. They stated (Brown and Root Services Asia Pacific Pty Ltd, 2001: 12-27):

TEMSIM is used as the basis of impact prediction and assessment for all the ... [proponent's] investigations. If the model is not accurate for operational scenarios then the predicted impacts will be wrong.

Nevertheless, the assessment body concluded that TEMSIM was a "reasonable predictive model" and that the proponent's use of the model was "a reasonable approach to adopt” (JAP, 2002b: 327). Incongruously, the assessment body also justified its favourable view of the model on the basis that "submitters suggested no other models or significant changes to TEMSIM" (JAP, 2002b: 327).

With their interrogation of the IIAS knowledge production process and their resultant view of it from very close range, the assessment body's consultants were concerned and explicit about the contingency of the proponent's environmental conclusions arising from TEMSIM and PROPHET. In contrast, at greater distance, the assessment body was satisfied that the proponent had done all it could to identify the environmental impacts.

\section{Formative value frameworks}

Having used the 'certainty trough' (MacKenzie, 1990: 372) to examine how the mechanics of impact assessment practice can influence the attribution of uncertainty in the process of knowledge production and obscure much from view, I now return to the issue of values raised by De Jongh (1988). I do so to discuss the implications of not unearthing these formative frameworks that are inevitably imposed by proponents by virtue of their role in the development of the impact statement.

Consultant 1 used past market behaviour to functionally operationalise its PROPHET model in terms of its price dispatch sequence (Duncan, 2004: Chapter 5). Accordingly, Consultant 1 reified in PROPHET and its outputs a particular view of the NEM and how actors would behave in it in the future, based predominantly on what had occurred in the past (IES, 2000a).

Similarly, in TEMSIM, informed by how it had operated in the past and how it hoped and expected to do so in the future (that is, as it had in the past in terms of its market share), the proponent embedded 


\section{The overriding formative value framework that underpinned both the PROPHET and TEMSIM models was that the past would be repeated in the future}

in its model unrealistic judgments about load, demand and how the Tasmanian electricity market might unfold (HEC 2001a; 2001b; Duncan, 2004). It also used past precipitation and storage levels in Tasmania to calculate what water should have been available for export, and this, in turn, informed its revenue forecasts.

Importantly, such predictions could have but did not take account of climate change or declining storage inflows that were apparently well-understood within the proponent's organisation and the Tasmanian government (Connarty, 2001b; Duncan, 2004: Chapter 2; HEC, 2001b; House of Assembly, 2003: 25 ). This was curious given that the proponent has been an ardent advocate for early action on climate change.

The overriding formative value framework that underpinned both the PROPHET and TEMSIM models was that the past would be repeated in the future (Evans, 1997). The following testimony from the public hearings shows how easy it was for the developers of PROPHET to pass on their contingent view of the world to the proponent. When questioned at public hearings about how price changes would affect the operating environment for the proponent over the 25-year agreement period, the proponent's representative replied (Connarty, 2001c):

it's been based on the prices input from ... [Consultant 1] data, so as far as that goes we're relying on them to model the market as accurately as possible and so they provided us with the price input data.

When questioned further about the price data, the proponent's representative said (Connarty, 2001c):

I'd have to get ... [Consultant 1] to actually discuss that. We weren't privy to the assumptions put into it. We were just supplied with that data and assumed it was representative of future Victorian prices. Again, we had no input. ... the assignment was to ... [Consultant 1] to supply suitable data for us to model the Basslink situation.

Of course, it could be argued, as the assessment body did, that the approach of Consultant 1 and the proponent was reasonable (see JAP, 2002b). However, the proponent openly divulged that it was unlikely that the past would be repeated in the future. The proponent was entering for the first time a market environment whereby "strategies will be employed to maximise energy trading values, and patterns of bidding will also reflect these broader financial objectives" (Locher, 2001a: 17). It was also revealed that "one aspect of the TEMSIM model which may vary depending on the future drivers for ....[the proponent], is the allocation of water value and energy" (Connarty, 2001a: 22). As long as these drivers stayed the same, TEMSIM would remain relevant in the future.

Notwithstanding these qualifications, the assessment body relied on the proponent's justifications about the reliability of the modelling it had presented (JAP, 2002b: 322-327). By the time the environmental conclusions were presented to the project's government decision-makers, the premise that the past would be repeated in the future which circumscribed the original and subsequent model inputs and outputs had already been disconnected from its contingencies and effectively deemed non-negotiable.

Yet, it is difficult to see what other options were left open to the assessment body, given its political imperative to finalise the assessment process and deliver a decision, as well as its constraints with respect to time and money. While the assessment body requested the proponent to revisit the load sensitivity analyses with different assumptions, and sought further answers on many queries and issues raised during the public hearings (see JAP, 2002b), the problem was that, by this stage of the process, the models had been constructed and the simulations run: the economic and environmental case had already been stitched up - it could not be undone.

To date, reality has displayed the folly of the proponent's worldview. In such a view, the continuation of a national government subsidy for renewable energy projects would have made available revenue for the proponent to build its planned wind farms to augment domestic supply and thereby free up hydroelectricity export capacity (HEC, 2001a: 5); precipitation levels and exports across the cable would have been at levels sufficient to derive revenue to cover the cable's original and revised facility fee, to make a profit and return funds to the government; also, the project cost and annual facility fee would have remained within initial estimates.

In stark contrast to the future embedded in the models and subsequent data sets constructed in 2000 and 2001, the federal government did not extend the renewable energy subsidy, ${ }^{4}$ the annual facility fee virtually doubled to around $\$ 92$ million per year owing to unexpected project and finance costs (Bevilacqua, 2003; Hydro Tasmania, 2003; NSR Environmental Consultants Pty Ltd, 2002: 12) and, because of consistently low storage inflows not adequately accounted for in the modelling, there 
have been few opportunities to export into the NEM. Instead, the proponent has had to import electricity across Basslink at prices much higher than originally anticipated. It has also had to buy natural gas for its back-up generation to assist in satisfying domestic demand (Hydro Tasmania, 2007). Ominously, as well as calling on the state government for a \$300 million cash injection (The Mercury, 1 June 2006), the proponent has declared that it will not be in a position to pay a dividend to the government in 2008.

In 2004, 2005 and 2006 it paid \$40 million and in 2007 just over \$20 million (Hydro Tasmania, 2005; 2007), but the proponent has stated that after 2008, "in the absence of an equity injection, dividends have been limited to $\$ 10$ million per annum, subject to profitability” (Hydro Tasmania, 2007: 32). Moreover, in July 2007, the Office of the Tasmanian Energy Regulator (2007) determined that residential electricity prices would increase by $15.7 \%$ in 2008 and a further 4\% in July 2008 and July 2009. ${ }^{5}$

In yet another twist, which could work in the hydro-generator's favour, the project's final approval contained a requirement for the proponent to undertake only six years of post-Basslink monitoring and adaptive management. Given the depleted storages and the likelihood that it will be some time before they can be replenished (assuming they will be), it is probable that any export-induced environmental impacts will occur outside the prescribed monitoring and adaptive management period. For instance, without mitigation, the identified environmental impacts on the Gordon River included an increased probability of river bank scour (Koehnken et al, 2001), a loss of riparian vegetation 1.5 metres beyond an existing dead-zone along the riverbanks (Davidson and Gibbons, 2001a: 11) and the loss of macroinvertebrate assemblages (Davies and Cook, 2001). ${ }^{6}$

\section{Conclusions: the implications of buried uncertainty}

Current practice appears necessary and justifiable to meet the often conflicting objectives of public

The pervasive use of predictive models by multiple teams of consultants serves to diminish the disclosure of uncertainty. As the credibility of a proponent's claims appears to strengthen, the contingencies would be multiplying with each modelling iteration disclosure and epistemic rigour, especially in integrated assessments where there are inherent linkages between economic production, social outcomes and environmental impacts. The analysis in this paper suggests, however, that what is currently accepted as standard procedure could be obstructing the very objectives the process is intended to deliver.

From a constructivist-STS perspective, the cumulative epistemic outcome of integrated impact assessment practice - which could also be seen as its triumph - is the appearance of the diminution of uncertainty; see also Duncan (2003). As the credibility of a proponent's claims appears to strengthen, the contingencies would be multiplying with each modelling iteration.

The Basslink case study demonstrates how current integrated impact assessment practice can create considerable distance between knowledge 'producers' and knowledge 'users', and eventually sever their connections. To the extent that these roles become interchangeable, collaborating actors are constituted in the 'certainty trough' (MacKenzie, 1990: 372), thus compromising the evidence relied upon in deliberations concerning whether or not a major project should proceed and on what conditions.

Hence, unless explicit clarifications are called for, what has become standard procedure would serve to isolate actors contributing to the development of an integrated impact statement. This isolation would diminish disclosure between collaborating consultants as well as to the impact statement audience, be they supporters, critics, regulators, assessors or decision-makers. Therefore, the reliability of the conclusions presented in impact statements would not be attributable to the rigorous challenge or peer-review of a proponent's claims, but rather to 'imposed trust' between actors required to collaborate at the behest of a proponent.

Although he suggests it should not be taken too literally, MacKenzie (1990: 393) uses the metaphor of a Russian doll to describe a technology on the basis that it is really not just one 'black box' but many, one inside the other. This progressive 'blackboxing' imagery is useful here for envisioning how a proponent's values are perpetuated in the movement of knowledge claims - although configured differently, each modelling exercise shares a striking resemblance.

Also highlighted is the fact that the 'independence' which proponents inevitably claim for the consultants they engage can only be partial. It has been shown that conclusions represented as 'scientific' and thereby 'independent' can not only rest on but perpetuate a proponent's partisan worldview about how its project is expected or hoped to operate in the future. Hence, the Russian doll metaphor draws attention to a proponent's influence over a project's regulatory outcomes by virtue of providing its consultants with their foundational and contingent baseline data.

Tennøy et al (2006: 55) maintain that "if EIA is to be a good decision-aiding tool, it must be because it 
gives decision-makers a better understanding of the consequences of their decisions”. The analysis presented here contends that what has become standard practice - the pervasive use of predictive models by multiple teams of consultants - currently serves to diminish the disclosure of uncertainty. The epistemic ramifications are that over-confidence has become instilled in the assessment process.

Problematically, current practice does not explicitly recognise this shortfall, and so procedures that might address it are deemed non-obligatory or simply unnecessary. For example, with over-confidence comes an assessment body's decision not to require a proponent to consider and explicitly disclose worst-case economic, social and environmental scenarios. As a consequence, proponents are not required to set out their contingency plans for such eventualities.

Further still, decision-makers do not mandate post-auditing of projects to test the veracity of the framings and futures embedded within a proponent's conclusions. For example, post-auditing is an essential tool for learning from experience (Flyvbjerg et al, 2002; 2003; Glasson et al, 2005), and would have constructive consequences for process transparency and proponent accountability by instigating substantial reform at the front-end of the process (Dipper et al, 1998; Wood et al, 2000).

It is difficult to see how the objectives of process transparency and proponent accountability in impact assessment can be met if proponents' formative value frameworks are not systematically identified and opportunities carved out for them to be challenged, negotiated and, where necessary, changed. Nor can these objectives be met if it is not recognised that uncertainty blind-spots are an inherent characteristic of what appears to have become indispensable integrated impact assessment practice.

By locating these vulnerabilities and examining their broader epistemic ramifications, it is hoped that this analysis can contribute to the reform of current practice and demonstrate the necessity of precautionary and mitigative strategies that "plan to learn, design for surprise and manage for adaptation” (Gibson et al, 2005: 111).

\section{Acknowledgements}

I would like to thank Aud Tennøy and two anonymous referees for their reviews and comments on earlier versions of this paper.

\section{Notes}

1 For commentary on and a critique of MacKenzie's 'certainty trough' (1990: 372), see Lahsen (2005), who modifies the distribution's configuration in the context of climate change science and the use of general circulation models.

2 The idea of combining certainty troughs comes from Shackley and Wynne (1995: 122) in their discussion of 'overlapping certainty troughs'. A distinction is being made here as overlapping would put the troughs out-of-phase, whereas when overlaid the compounding outcome of integrated impact assessment practice on uncertainty disclosure is captured.

3 This compounding effect also has implications for those at greatest distance from the location of knowledge production but not in support of a project. Figure 3 shows that these actors will perceive potentially inordinate levels of uncertainty. This phenomenon was reflected in several Basslink public submissions of critics who made very lengthy comments on the draft IIAS in excruciatingly minute detail.

4 However, it should be noted that a change in the national government in late 2007 has seen a commitment to now extend the renewable energy subsidy.

5 The regulator stated that around half the increase was due to Tasmania's energy retailer, Aurora Energy, having to pay higher prices to purchase electricity from the hydro-generator proponent.

6 Although the proponent would argue that these impacts will be mitigated, Duncan (2006) discusses the limitations of the proponent's predictive modelling and its claims about the modelled effect of mitigation on full capacity discharges. In addition, Duncan and Hay (2007) document the conditions the proponent placed on its mitigation commitments and argue that these are likely to serve to erode rather than enhance the environmental quality of the Gordon River.

\section{References}

Beder, S 1993. Bias and credibility in environmental impact assessment. Chain Reaction, 68, 28-30.

Bevilacqua, S 2003. Basstink: Row erupts over electricity project's $\$ 250 \mathrm{~m}$ blowout. The Sunday Tasmanian, 15 June 2003. Hobart: Davies Brothers Pty Limited.

Bohme, G 1997. The structures and prospects of knowledge society. Social Science Information, 36(3), 447-468.

Brown and Root Services Asia Pacific Pty Ltd 2001. Independent Review of the Draft Integrated Impact Assessment Statement, report prepared for Basslink Joint Advisory Panel. Melbourne: Brown and Root Services Asia Pacific Pty Ltd.

Clayton Utz 2001. Hydro Tasmania's Opening Submission: Part 1 - Introduction. Hobart: Resource Planning and Development Commission.

Collins, H M 1987. Certainty and the public understanding of science: science on television. Social Studies of Science, 17(4), $689-713$.

Collins, H M 1988. Public experiments and displays of virtuosity: the core-set revisited. Social Studies of Science, 18(4), $725-748$.

Connarty, M 2001a. Appendix 29: TEMSIM Sensitivity Study on Implications of Basslink, prepared for Hydro-Electric Corporation. Hobart: Resource Planning and Development Commission.

Connarty, M 2001b. Response to TEMSIM Modelling Issues Arising from the Basslink IIAS, prepared for Hydro-Electric Corporation. Hobart: Resource Planning and Development Commission.

Connarty, M 2001c. Transcription of audio evidence presented at Public Hearings, 15 October.

CREA, Centre for Regional Economic Analysis 2000. The Economic Consequences of Basslink for the Tasmanian, Victorian and National Economies. Hobart: University of Tasmania.

Davidson, N and A Gibbons 2001a. Appendix 6: Gordon River Riparian Vegetation Assessment, DIIAS report prepared for Hydro Tasmania. Hobart: Resource Planning and Development Commission.

Davidson, N and A Gibbons 2001b. Gordon River Riparian Vegetation Assessment Update to IIAS, report prepared for Hydro Tasmania. Hobart: Resource Planning and Development Commission.

Davies, P D 2001. Gordon River Macroinvertebrate and Aquatic Mammal Assessment Update to IIAS, report prepared for $\mathrm{Hy}$ dro Tasmania. Hobart: Resource Planning and Development Commission.

Davies, P D and L S J Cook 2001. Appendix 7: Gordon River Macroinvertebrate and Aquatic Mammal Assessment, draft IIAS report prepared for Hydro Tasmania. Hobart: Resource Planning and Development Commission.

De Jongh, P 1988. Uncertainty in EIA. In Environmental Impact Assessment: Theory and Practice, ed. P Wathern, pp. 63-84. London: Routledge.

Dipper, B, C Jones and C Wood 1998. Monitoring and post-auditing 
in environmental impact assessment: a review. Journal of Environmental Planning and Management, 41(6), 731-747.

Duncan, R 2003. Constructing barriers in the translation and deployment of science: Basslink - a case study. Australian Journal of Public Administration, 62(1), 80-87.

Duncan, R 2004. Science narratives: the construction, mobilisation and validation of Hydro Tasmania's case for Basslink PhD thesis. Hobart: School of Geography and Environmenta Studies, University of Tasmania. Available at <http://eprints. utas.edu.au/238/>, last accessed 22 February 2008.

Duncan, R 2006. The use of predictive modelling in impact assessment: implications for environmental legislation and regulation. Australian Journal of Public Administration, 65(1), 75-88.

Duncan, $R$ and $P$ Hay 2007. A question of balance in integrated impact assessment: negotiating away the environmental interest in Australia's Basslink project. Journal of Environmental Assessment Policy and Management, 9(3), 273-297.

Evans, R 1997. Soothsaying or science?: Falsification, uncertainty and social change in macroeconomic modelling, Social Studies of Science, 27, 395-438.

Flyvbjerg, B, J S Holm and S Buhl 2002. Underestimating costs in public works projects: error or lie? Journal of the American Planning Association, 68(3), 279-295.

Flyvbjerg, B, N Bruzelius and W Rothengatter 2003. Megaprojects and Risk: An Anatomy of Ambition. Cambridge: Cambridge University Press.

Genelletti, D, E Beinat, C F Chung, A G Fabbri and H J Scholten 2003. Accounting for uncertainty factors in biodiversity impact assessment: lessons from a case study. Environmental Impact Assessment Review, 23, 471-487.

Gibson, R, S Hassan, S Holtz, J Tansey and G Whitelaw 2005. Sustainability Assessment: Criteria and Processes. London: Earthscan.

Glasson, J 1994. Life after the decision: the importance of monitoring in environmental impact assessment. Built Environment 20(4), 309-320.

Glasson, J, R Therivel and A Chadwick 2005. Introduction to Environmental Impact Assessment, 3rd edn. London: Routledge.

Gubrium, J F and J A Holstein 2000. Analyzing interpretive practice. In Handbook of Qualitative Research, 2nd edn, eds. N K Denzin and Y S Lincoln, pp. 487-507. Thousand Oaks: Sage.

Hartmann, S 1996. The world as a process: simulations in the natural and social sciences. In Modelling and Simulation in the Social Sciences from the Philosophy of Science Point of View, eds. R Hegselmann, U Mueller and K G Troitzsch, pp. 77-100. Dordrecht: Kluwer.

HEC, Hydro-Electric Corporation 2001a. Hydro Tasmania Business and Economic Issues. Hobart: Resource Planning and Development Commission.

HEC, Hydro-Electric Corporation 2001b. TEMSIM Modelling Hobart: Resource Planning and Development Commission.

Hilgartner, S 2000. Science on stage: expert advice as public drama. Stanford: Stanford University Press.

House of Assembly 2003. Hansard, Tuesday 18 February 2003: House of Assembly Government Businesses Scrutiny Committee. Hobart: Parliament of Tasmania. Available at <http://www. hansard.parliament.tas.gov.au>, last accessed 19 July 2003.

Howland, M 2001. Gordon River Fish Assessment Update to IIAS draft IIAS report prepared for Hydro Tasmania. Hobart: Resource Planning and Development Commission.

Hydro Consulting 2000. Appendix 1: Scoping Report, Basslink Aquatic Environmental Project, draft IIAS report prepared for Hydro Tasmania. Hobart: Resource Planning and Development Commission.

Hydro Tasmania 2003. Letter to editor. The Examiner, 6 June 2003. Launceston: Davies Brothers Pty Limited.

Hydro Tasmania 2005. Hydro Tasmania Report 05. Hobart: Hydro-Electric Corporation.

Hydro Tasmania 2007. Hydro Tasmania Annual Report 07. Hobart: Hydro-Electric Corporation.

IES, Intelligent Energy Systems 2000a. Supporting Study 20 : Macro-economic NEM Modelling (Vic \& Tas), draft IIAS report prepared for Basslink Pty Ltd. Hobart: Resource Planning and Development Commission.

IES, Intelligent Energy Systems 2000b. Supporting Study 14: Greenhouse Gas NEM Modelling (Vic \& Tas), draft IIAS report prepared for Basslink Pty Ltd. Hobart: Resource Planning and Development Commission.

IES, Intelligent Energy Systems 2002. PROPHET: The Essential Tool for Electricity Market Participants. Available at <http://www.intelligentsys.com.au/ies/prophetintro.html>, last accessed 8 December 2002.

Irwin, A 2001. Sociology and the Environment: A Critical Introduction to Society, Nature and Knowledge. Cambridge: Polity Press.

Irwin, A and B Wynne 1996. Introduction. In Misunderstanding Science? The Public Reconstruction of Science and Technology, eds. A Irwin and B Wynne, pp. 1-17. Cambridge: Cambridge University Press.

JAP, Joint Advisory Panel 2002a. Draft Panel Report. Hobart: Resource Planning and Development Commission.

JAP, Joint Advisory Panel 2002b. Final Panel Report. Hobart: Resource Planning and Development Commission.

Jasanoff, S 1987. Contested boundaries in policy-relevant science. Social Studies of Science, 17, 195-230.

Jasanoff, S 1990. The Fifth Branch: Science Advisers as Policymakers. Cambridge MA: Harvard University Press.

Koehnken, L 2001. Gordon River Fluvial Geomorphology Assessment Update to IIAS, draft IIAS report prepared for Hydro Tasmania. Hobart: Resource Planning and Development Commission.

Koehnken, L, H Locher and I Rutherfurd 2001. Appendix 4: Gordon River Fluvial Geomorphology Assessment, draft IIAS report prepared for Hydro Tasmania. Hobart: Resource Planning and Development Commission.

Kriwoken, L K 2001a. Appendix 14: Gordon River World Heritage Area Values Assessment, draft IIAS report prepared for Hydro Tasmania. Hobart: Resource Planning and Development Commission.

Kriwoken, L K 2001b. Gordon River World Heritage Area Values Assessment Update to the IIAS, draft IIAS report prepared for Hydro Tasmania. Hobart: Resource Planning and Development Commission.

Lahsen, M 2005. Seductive simulations? Uncertainty distribution around climate models. Social Studies of Science, 35(6), 895-922.

Latour, B 1987. Science In Action. How to Follow Scientists and Engineers Through Society. Cambridge MA: Harvard University Press.

Latour, B and S Woolgar 1979. Laboratory Life: The Social Construction of Scientific Facts. Beverly Hills: Sage.

Locher, H 2001a. Summary Report, draft IIAS report prepared by Hydro Tasmania. Hobart: Resource Planning and Development Commission.

Locher, H 2001b. Overview Report on Tasmanian Waterway Issues Arising from Basslink, draft IIAS report prepared by Hydro Tasmania. Hobart: Resource Planning and Development Commission.

MacKenzie, D 1990. Inventing Accuracy: A Historical Sociology of Nuclear Missile Guidance. Cambridge MA: MIT Press.

MacKenzie, D 2007. Personal email correspondence, 2 August.

NSR Environmental Consultants Pty Ltd 2001. Draft Integrated Impact Assessment Statement. Hawthorn East: NSR Environmental Consultants.

NSR Environmental Consultants Pty Ltd 2002. Final Environmental Impact Statement and Supplement to the Draft Integrated Impact Assessment Statement. Hawthorn East: NSR Environmental Consultants.

Office of the Tasmanian Energy Regulator 2007. Media Release: Electricity Price Investigation Final Report Released. 28 September. Available at <http://www.energyregulator.tas.gov.au/ domino/otter.nsf/otter-v/002>, last accessed 22 February 2008.

Porter, T M 1992a. Quantification and the accounting ideal in science. Social Studies of Science, 22, 633-652.

Porter, T M 1992b. Objectivity as standardization: the rhetoric of impersonality in measurement, statistics, and cost-benefit analysis. Annals of Scholarship, 9, 19-59.

Porter, T M 1995. Trust in Numbers: The Pursuit of Objectivity in Science and Public Life. New Jersey: Princeton University Press.

Shackley, S and B Wynne 1995. Integrating knowledges for climate change: pyramids, nets and uncertainties. Global Environmental Change, 5(2), 113-126.

Shackley, S and B Wynne 1996. Representing uncertainty in global climate change science and policy: boundary-ordering devices and authority. Science, Technology \& Human Values, 21(3), 275-302.

Smith, R D 1999. Simulation: the engine behind the virtual world. Available at <http://www.modelbenders.com/papers/sim2000/ SimulationEngine.PDF>, last accessed 20 February 2008.

Spry, A 1976. A Consultant's Views on Environmental Impact Statements in Australia. Search, 7(6), 252-255. 
Strand, S 1999. Forecasting the future: pitfalls in controlling for uncertainty. Futures, 31, 333-350.

Tennøy, A 2008. Consequences of environmental impact assessment prediction uncertainty on mitigation, follow-up and post-auditing. In Standards and Thresholds for Impact Assessment, eds. M Schmidt, J Glasson, L Emmelin and $\mathrm{H}$ Helbron, pp. 447-458. New York: Springer.

Tennøy, A, J Kværner and K I Gjerstad 2006. Uncertainty in environmental impact assessment predictions: the need for better communication and more transparency. Impact Assessment and Project Appraisal, 24(1), March, 45-56.

Thomas, I 1998. Environmental Impact Assessment in Australia: Theory and Practice, 2nd edn. Leichhardt: Federation.
URS New Zealand Ltd 2001. Supporting Study 15: Greenhouse Gas Assessment (Vic \& Tas), draft IIAS report. Hobart: Resource Planning and Development Commission.

Wachs, M 1990. Ethics and advocacy in forecasting for public policy. Business and Professional Ethics Journal, 9(1-2), 141-157.

Wood, C, B Dipper and C Jones 2000. Auditing the assessment of the environmental impacts of planning projects. Journal of Environmental Planning and Management, 43(1), 23-47.

Wynne, B 1992a. Uncertainty and environmental learning: reconceiving science and policy in the preventive paradigm. Global Environmental Change, 2, June, 111-127.

Wynne, B 1992b. Carving out science (and politics) in the regulatory jungle. Social Studies of Science, 22, 745-758. 


\section{Impact Assessment and Project Appraisal Journal of the International Association for Impact Assessment}

\section{The Association}

Values IAIA promotes the application of integrated and participatory approaches to impact assessment, conducted to the highest professional standards. IAIA believes the assessment of the environmental, social, economic, cultural and health implications for proposals to be a critical contribution to sound decision-making processes, and to equitable and sustainable development.

Vision IAIA is the leading global network on the best practice in the use of impact assessment for informed decision making regarding policies, programs, plans, and projects.

Mission IAIA provides an international forum for advancing innovation and communication of best practice in all forms of impact assessment to further the development of local, regional and global capacity in impact assessment.

For information about IAIA, contact Rita Hamm, Chief Executive Officer, IAIA International Headquarters, 1330 23rd Street South, Suite C, Fargo, ND 58103-3705, USA; Tel: +1 701297 7908; Fax: +1 701297 7917; Email: info@iaia.org. The Association's website is http://www.iaia.org

\section{The journal}

Addresses on inside back cover Co-editors: Colin Kirkpatrick, Impact Assessment Research Centre, School of Environment and Development, University of Manchester, UK, and Carys E Jones, EIA Centre, School of Environment and Development, University of Manchester, UK.

Editorial Associate: Jennifer Franz, Impact Assessment Research Centre, School of Environment and Development, University of Manchester, UK.

Book Review Editors: Angus Morrison-Saunders, Murdoch University, Australia, and Maria Partidário, Technical University of Lisbon, Portugal.

\section{Editorial board}

Elvis Au Environmental Protection Dept, Hong Kong SAR Government Charlotte Bingham Millennium Challenge Corp, Washington DC, USA Alan Bond University of East Anglia, UK

Larry Canter EI Training, Horseshoe Bay, USA

Jenny Dixon University of Auckland, New Zealand

Richard Fuggle University of Cape Town, South Africa

Angus Morrison-Saunders Murdoch University, Australia

Bram Noble University of Saskatchewan, Canada

John Page Parsons Brinckerhoff Quade and Douglas Inc, USA

Maria Partidário IST, Technical University of Lisbon, Portugal

Jenny Pope Murdoch University, Australia

Francois Retief North-West University, South Africa

Suresh Rohilla University of Bradford, UK

Pierre Senécal Hydro-Québec, Montréal, Canada

Wil A H Thissen Delft University of Technology, The Netherlands

Typeset in Times by Hilary Soper, Beech Tree Publishing and printed by EntaPrint, Cranleigh, Surrey, UK on all reclaimed, acid-free paper.

\section{Publication details}

IAPA is published for IAIA by Beech Tree Publishing, 10 Watford Close, Guildford, Surrey GU1 2EP, UK; Tel: +44 1483 824871; Email: page@scipol.co.uk. Production assistant: Alice Yew; publisher: William Page. ISSN 1461-5517 Published quarterly (March, June, September, December)

\section{Library subscription prices, 2008}

Send all library orders to Beech Tree, address above. Prices for 12 months, print + free online $(\mathrm{p}+\mathrm{fo})$ including air-speeded mail: if in Europe, Australia, New Zealand, USA, Canada, Japan: $£ 158$, US\$278, €258; online only: £142, US\$250, $€ 232$. Everywhere else, $\mathrm{p}+\mathrm{fo}$ : $£ 116$, US\$203, $€ 188$; online only: £104, US\$183, €169. Trial 6 months: ask us. Single print copies: $£ 40$, US\$71, $€ 66$ (or for members of IAIA: £12, US\$24, €19); single copies online: see Ingenta website, below. Checks payable to Beech Tree Publishing; or MasterCard or Visa; or inter-bank transfer.

VAT tax applies only to online-only orders; if in the UK - or in another EU state and are NOT registered for VAT — then please add $17.5 \%$.

Open access: All items in IAPA become open access 24 months after publication on www.ingentaconnect.com/content/beech/iapa. Non-subscribers can pay to view more recent items.

IAIA membership: fees to June 2008

IAIA membership includes subscription to IAPA. Individual membership, all countries: US\$100; joint membership US\$135; student US\$50; institutional/corporate ask IAIA. Pay in US funds, or by MasterCard or Visa, to IAIA in Fargo (see left-hand column).

\section{Photocopies and copyright}

Copyright (C) International Association for Impact Assessment 2008. All Rights Reserved. No part of this publication may be reproduced, stored in a retrieval system, or transmitted, in any form or by any means, electronic, mechanical, photocopying, recording, scanning or otherwise, except as described below, without the permission in writing of the publisher.

Copying of articles is not permitted except for personal and internal use, to the extent permitted by national copyright law, or under the terms of a licence issued by the national Reproduction Rights Organisation (such as the UK's Copyright Licensing Agency). Fees appear in the code at the foot of the first page of each article. Send requests for permission for other kinds of copying to William Page at page@scipol.co.uk. 